\title{
Documentalistas indígenas en procesos de colaboración comunitaria en Chiapas
}

\section{Indigenous documentalists in processes of community collaboration in Chiapas}

- Sarelly Martínez y Zaira Coutiño

Universidad Autónoma de Chiapas, México

Fecha de recepción: 28 de marzo de 2019

Fecha de aprobación: 1 de julio de 2019

DOI: http://dx.doi.org/10.15304/ricd.3.10.5920

\section{NOTAS BIOGRÁFICAS}

Sarelly Martínez es profesor en la Universidad Autónoma de Chiapas, México y doctor en Ciencias de la Información por la Universidad Complutense de Madrid.

Contacto: sarellym@gmail.com

Zaira Coutiño es licenciada en Comunicación y magíster en Estudios Culturales por la Universidad Autónoma de Chiapas. Fue coordinadora general de la muestra de video documental indígena La cosmovisión indígena a través del video.

Contacto: geraldine_2810@hotmail.com

\section{Resumen}

A fines del siglo pasado, jóvenes indígenas de Chiapas, México, apoyados por antropólogos, sociólogos y cineastas, empezaron a videograbar sus comunidades. Al paso del tiempo, un grupo de 37 personas, entre las que se encuentran 12 mujeres, se dedican a la realización de documentales. Su pretensión es construir la memoria colectiva de comunidades indígenas y posicionar en la agenda mediática las necesidades y prácticas culturales de esas poblaciones que representan casi un tercio de los habitantes de Chiapas. En este trabajo, fundamentado en una metodología etnográfica, participaron siete documentalistas que pertenecen a las cuatro etnias principales de ese estado (tzotzil, tzeltal, zoque y tojolabal). El propósito del texto es describir e interpretar las prácticas colaborativas que surgen en el proceso de creación de documentales indígenas, desde el ingreso a la comunidad, con los permisos que se deben obtener para la grabación, la elección del tema, de los personajes y la posterior exhibición en lugares públicos de la población en donde se realizó la videograbación. Este proceso de colaboración, que los documentalistas han aprendido sobre la marcha, arroja como resultado un material audiovisual que es enriquecido por diferentes miradas, y que refleja las necesidades y sentires de una comunidad respecto a sus danzas, convivencia con la naturaleza, prácticas tradicionales médicas, ceremonias religiosas, defensa de terrenos comunales, y todos aquellos temas que consideren que debe videograbarse para preservar su memoria colectiva.

\section{Abstract}

At the end of the last century, young indigenous people of Chiapas, Mexico, with the support of anthropologists, sociologists and filmmakers, started to record their communities on camera. As time has gone on, a group of 37 people, among them 12 women, have dedicated themselves to the making of 
documentaries. Their aim is to build the collective memory of indigenous communities and to put the cultural needs and practices of these populations, which represent almost a third of the Chiapas habitants, on the media's agenda. In this project, based on an ethnographic methodology, seven documentalists participated. They remained true to the four ethnic principles of this state (tzotzil, tzeltal, zoque and tojolabal). The purpose of the commentary is to describe and interpret the collaborative practices that emerge in the indigenous documentary creation process, from entering the community -and obtaining all the necessary permits for filming-, to choosing the topic, the people featured and organising the postdocumentary exhibition in public places where all the filming was made. This collaboration process, which documentalists have learnt on the go, results in an audio-visual product that has been enriched by differing perceptions. It reflects the needs and sentiments of a community with respect to their dances, coexistence with nature, traditional medical practices, religious ceremonies, communal area defence, and everything which they consider important to be recorded, in order to preserve their collective memory.

\section{Palabras clave}

Documental, Documental indígena, Investigación colaborativa, Desarrollo cultural comunitario, Chiapas.

\section{Keywords}

Documentary, Indigenous documentary, Collaborative research, Community cultural development, Chiapas.

\section{Sumario}

1. Introducción

1.1. Documental indígena

2. Apunte metodológico

3. Proceso creativo de colaboración

3.1 Acercamiento y diálogo con la comunidad

3.2 Personajes y escaletas

3.3 Mediador artístico

3.4 Colaboración entre académicos, cineastas y documentalistas

3.5 Exhibición en las comunidades

4. Conclusiones

\section{Contents}

1. Introduction

1.1 Indigenous documentary

2. Methodological note

3. Collaborative creative process

3.1 Approach and dialogue with the community

3.2 Characters and runners

3.3 Artistic mediator

3.4 Collaboration between academics, filmmakers and documentalists

3.5 Exhibition of documentaries

4. Conclusions 


\section{INTRODUCCIÓN}

En los estados de Oaxaca y Chiapas, México, han surgido documentalistas indígenas que en sus comunidades registran danzas, prácticas médicas, ceremonias religiosas, aspectos de organización social, protestas por la defensa de terrenos comunales y llamados a convivir de una manera más equilibrada con la naturaleza. No es un fenómeno exclusivo de estos estados, pero sí en donde se concentra la producción documental más numerosa del país. En Chiapas, ubicamos en esta investigación a 37 documentalistas, de los cuales 22 son tzotziles, 11 tzeltales, 2 tojalabales, 2 zoques y 1 chol. De ese número, 12 son mujeres.

La aparición de documentalistas indígenas es producto de la globalización, de la mundialización de las tecnologías de la información y de la iniciativa de jóvenes indígenas que, acompañados de antropólogos, sociólogos, etnógrafos y cineastas, decidieron apropiarse de técnicas occidentales para recrear la memoria de sus pueblos. Forman parte de una escuela de documentalistas que propusieron otras miradas sobre el audiovisual, dentro de la corriente etnográfica, en la que destacan Robert Flaherty, por argumentar que el documental debe "promover la mutua comprensión entre los pueblos" (Colombres, 1985, p. 57); Dziga Vertov, por su defensa de un cine-ojo, de objetividad absoluta (Hicks, 2007); Jean Vigo, por su "punto de vista documentado" (Colombres, 1985, p. 15), y, por supuesto, Jean Rouch, la figura monumental dentro de esta corriente, por su "antropología compartida" con el cine verdad (Henley, 2009, p. 355). En América Latina fue fundamental la aportación de Jorge Sanjinés, quien mostró problemas, derechos y demandas de los pueblos marginados, como una vía de "expresión de culturas, no de personas" (FMPachá 973, Entrevista a Iván Sanjinés, 17 de noviembre de 2012).

En el periodo que va de Flaherty, Vertov, Vigo, pasando por Rotha, Rouch y Sanjinés, fueron los mestizos quienes "prestaban" técnicas y grababan a los actores para exponer la riqueza cultural de los pueblos indígenas. En México, Nicolás Echevarría trabajó con diversos grupos étnicos, así como Francisco Urrusti y Luis Lupone, quienes videograbaron rituales de chamanismo y consumos de hongos alucinógenos y peyotes. Antropólogos, arqueólogos, periodistas y cineastas se acercaron a las comunidades para grabar celebraciones religiosas. Incluso, la escritora chiapaneca Rosario Castellanos (1925-1974) escribió en 1958 el guion Todos somos mexicanos, financiado por el Instituto Nacional Indigenista (INI). Pero eran los otros, los de fuera, quienes realizaban las producciones sin que el material, que era expuesto en reuniones académicas o en muestras de cine, estuviera accesible a la comunidad.

La transferencia de la cámara de especialistas a indígenas se registró a principios de los ochenta, cuando un grupo de jóvenes utilizó una cámara Betamax para grabar una celebración de San Juan Tagui, en Oaxaca. El grupo no tenía más pretensión que los participantes pudieran verse a sí mismos, lo cual logró mediante una exhibición pública en la misma localidad. Después, Luis Lupone, cineasta de origen italiano, capacitó a tejedoras de la comunidad huave de San Mateo del Mar, en Oaxaca, para que videograbaran sus actividades. Entre ellas estaba Teófila Palafox, quien había de convertirse en referencia en la producción de videos comunitarios. Por esas mismas fechas, el INI echó a andar el Programa Transferencia de Medios Audiovisuales a Comunidades y Organizaciones Indígenas con el propósito de que fueran los miembros de las comunidades que realizaran sus propios documentales. A ese programa, en donde participaron representantes de 37 organizaciones del país, asistieron cuatro indígenas chiapanecos (Ardévol y Muntañola, 2001). Los primeros resultados fueron desiguales: "narraciones 'en off' mal hechas, que reproducían lo que recibían de la televisión y radio comercial dominante" (Cusi, 2005, p. 34). Solo algunos documentales eran rescatables. Era normal que la producción fuera de ese tipo, porque los cursos eran breves y se limitaban al manejo de la cámara y a técnicas básicas de edición.

Esta etapa, aun con sus altibajos, fue clave en el descubrimiento y apropiación de cámaras y de discursos fílmicos, cada vez más propositivos y más alejados de la televisión comercial. Cada año, un número mayor de indígenas se iniciaba en el documentalismo, en una oleada que recorrió diversos países de América Latina, y que tuvo como propósito mostrar una realidad -la propia-, con todo lo que implicaba: riqueza cultural, tradiciones milenarias, formas de convivencia con la naturaleza, aplicación de técnicas agrícolas diferentes, disputas intercomunales y enfrentamientos con el Estado. Cineastas, antropólogos y guionistas se involucraron en la capacitación. Aparte del INI, 
con su programa de Transferencia de Medios, que operó por varios años, integrantes del Ejército Zapatista de Liberación Nacional (EZLN) implantaron en 1998 el Proyecto de Medios de Comunicación Comunitaria, A.C. (Promedios); ese mismo año, miembros The Chicago-Chiapas Media Project capacitaron y entregaron videocámaras a cuatro comunidades zapatistas con el propósito de documentar la entrada de los soldados a esos territorios (Darling, 2008) y en el 2000, los académicos Xóchitl Leyva y Axel Köhler, impartieron un Diplomado en Antropología Visual con Especialidad en Derechos Indígenas, que desembocó en el Proyecto de Videoastas Indígenas de la Frontera Sur.

Estas iniciativas coincidieron en la propuesta de que fueran los indígenas quienes grabaran y armaran los discursos audiovisuales de sus comunidades, lo que representó un viraje en la tradición documentalista, inserto en la perspectiva decolonial, de construcción de mensajes alternativos, ante la visión homogénea de la televisión y la radio comerciales. Actualmente, los documentalistas indígenas chiapanecos registran temas variados, pero relacionados con la vida y preocupaciones de sus comunidades.

\subsection{DOCUMENTAL INDÍGENA}

A las realizaciones videográficas que dirigen personas de procedencia indígena se les ha asignado diferentes nombres: video indígena, cine indígena o documental indígena. El término video indígena es cuestionado por los realizadores, porque consideran que su uso encasilla y refiere a una producción estereotipada y artesanal (Jiménez, comunicación personal, 21 de enero de 2018), pero a otros no les preocupa tal denominación, porque para ellos lo importante es la calidad del trabajo: "si tiene una estética más audaz y experimental", y un "propio estilo", puede competir en festivales internacionales con películas no indígenas (Barbeau, 2013). Leyva y Köhler (2008) prefieren hablar de "videos híbridos producidos por indígenas". En este texto, optamos por emplear el término documental, seguido por la palabra indígena, porque remite al acto de "captar una realidad" dentro de una comunidad étnica, con "su propia identidad" (Smith, 1999, p. 31).

El documental posee características que le ha permitido adaptarse a las comunidades indígenas, como su bajo costo en la realización, su propósito de reflejar la "realidad", propiciar el diálogo intercultural, empoderar a los ciudadanos, impulsar el desarrollo cultural, configurar la memoria colectiva y, sobre todo, y es lo que nos interesa profundizar en este texto, fomentar el trabajo colaborativo y artístico en las comunidades. No hablamos de "antropología compartida", como lo propuso Rouch, porque como bien señalan Leyva y Köhler (2008), esta acepción tiene "un dejo paternalista", al remitir a la idea de cuando "un propietario permite a otros el uso, el goce o posesión parcial de una cosa", y este proceso es más bien colaborativo, al "trabajar con otra u otras personas en la realización de una obra" (Diccionario de la Lengua Española, 2019).

A continuación, enumeramos las características del documental indígena, y para ello nos hemos apoyado en las aportaciones de Bill Nichols (1997, 2016), Colombres (1985), Ardévol y Muntañola (2001), Zirión (2015) y de los posicionamientos de Rotha, Rouch y Sanjinés.

Bajo costo. El documental, a diferencia del cine de ficción, puede realizarse con poca inversión económica, debido a que el equipo de filmación ha registrado precios cada vez más accesibles, y los protagonistas, cuando cobran, los gastos por sus apariciones no son muy altos. Las tecnologías actuales de comunicación permiten que comunidades, a las que se les había negado la posibilidad de habla (Spivak, 2009), construyan ahora un discurso hilvanado por miembros de su comunidad. Es común, además, que varios documentalistas indígenas cooperen para comprar equipo de filmación de uso colectivo.

Refleja la realidad. El documental enfatiza en el propósito de contar "una verdad", "una realidad", -aunque ésta resulte bastante cuestionable, como lo enfatizan Zunzunegui y Zumalde (2019) - con lo que se aleja de los terrenos de la ficción. Para realzar esta característica, Bill Nichols, uno de los teóricos más conocidos de este género, tituló su libro sobre el documental: Speaking Truths With Film; Evidence, Ethics, Politics in Documentary (2016). El documental "no pretende ser realista, sino real", afirman Pilar Carrera y Jenaro Talens (2018). Así, el documental indígena, como proyecto de hacer arte de lo real, se acerca al direct cinema y al cinéma vérité, que exigen la intervención mínima del director y de narradores, y el empleo de sonidos ambientales y de entrevistas. 
Poco control. A diferencia del cine de ficción, en el documental "los realizadores ejercen menos control sobre su tema" y "la historia" (Nichols, 1997, p. 42). A menudo esta característica sobresale cuando se define al documental, porque los directores controlan muy poco: los protagonistas tienen que expresar lo que sienten, la luz puede ser caprichosa y el sonido arruinar una buena toma.

Trabajo en equipo. El documentalista necesita de un equipo para concretar su trabajo, entre los que se cuentan sonidistas, camarógrafos y editores. Es posible que el documentalista desempeñe todas esas actividades, pero lo común es que se apoye en un equipo para lograr sus objetivos.

Colaboración. El documental indígena se caracteriza por emplear estrategias de colaboración y participación con la comunidad, al incorporar "de muy distintas maneras las voces, las ideas y las perspectivas de los otros, comparten con ellos la mirada y autoría como co-realizadores" (Zirión, 2015). Más que imponer su visión y su autoridad, el documentalista se convierte en mediador y enlace de la comunidad.

De estos cinco elementos que identifican al documental, nos detendremos en analizar el último aspecto, para conocer cómo se registran esos encuentros colaborativos entre el realizador, su equipo y la comunidad.

\section{APUNTE METODOLÓGICO}

De los 37 documentalistas indígenas identificados, decidimos trabajar con 8 que pertenecieran a las 4 etnias más importantes de Chiapas; sin embargo, al final, nos apoyaron (ver Anexo): Martiniano Hernández Gómez ${ }^{1}$ y Rosa Amelia Hernández Gómez ${ }^{2}$, tzotziles originarios de Chamula y de Zinacantán, respectivamente; Juan López Intzín ${ }^{3}$ y Maricela Sánchez Gómez", tzeltales de Tenejapa; Samuel Ávila Ledezma ${ }^{5}$ y Saúl Méndez Díaz ${ }^{6}$, zoques de Chapultenango y Rayón, y Elena Gomez Pérez ${ }^{7}$, tojolabal de Las Margaritas. Es decir, cuatro hombres y tres mujeres.

El objeto de esta indagación no fue examinar la calidad estética o de contenido de los documentales, sino describir y analizar las relaciones que establecen los documentalistas con las comunidades en donde graban sus imágenes. Para el logro de este propósito se optó por el enfoque etnográfico, caracterizado por involucrar un proceso descriptivo/interpretativo a través del cual se elabora una representación de lo expresado por los entrevistados y lo observado en el campo (Mora, 2010). Durante el trabajo de campo, se privilegió la observación participante y las entrevistas en profundidad lo que implicó convivir con los documentalistas, dialogar con ellos, acompañarlos a los pueblos para conocer los vínculos que cultivan en las comunidades.

\section{PROCESO CREATIVO DE COLABORACIÓN}

En este apartado describiremos y analizaremos la ruta colaborativa que sigue el documentalista, desde la entrada a la comunidad (con la cadena de permisos y apoyos), el trazo de una escaleta, el vínculo que establece con los participantes y autoridades, y finalmente, la exhibición del producto, en donde recoge las últimas observaciones de los personajes involucrados.

\subsection{ACERCAMIENTO Y DIÁLOGO CON LA COMUNIDAD}

La creación de un documental indígena implica un proceso de colaboración total. Documentalista, "actores" y autoridades locales deben tener acuerdos previos. La colaboración principia cuando el realizador solicita permiso a las autoridades y a los protagonistas para filmar la vida de la comunidad, y debe ser muy explícito sobre qué va a grabar y cómo; explicar los fines, personas que intervendrán, beneficiados, lugares de exhibición y comercialización. El permiso es un proceso lento que amerita reuniones, en donde se manifiestan dudas, disensos, se escuchan propuestas, se remarcan coincidencias y, a veces, solicitudes de apoyo material.

De manera esquemática, se puede decir que el documental inicia con la elección del tema, el cual se presenta a la comunidad para su aprobación; continúa con la localización de los personajes; la elaboración de una escaleta o guion (en algunos casos el documentalista improvisa o se apoya en un bosquejo que traza sobre la marcha), y la solicitud de financiamiento a organizaciones civiles 0 instituciones gubernamentales.

La ventaja del documentalista indígena es el vínculo que mantiene con las comunidades en 
donde trabaja, lo que le permite establecer acuerdos con mayor facilidad, tanto con las autoridades locales como con las familias o con los personajes que participarán en el documental. Rosa Amelia Hernández y su equipo audiovisual tuvieron dificultades en la comunidad Pozo Colorado, de Zinacantán, debido a que no solicitaron permiso para la grabación: "Nos querían linchar. Afortunadamente, al final, solo nos expulsaron, pero estaban muy enojados" (Hernández, comunicación personal, 20 de febrero de 2018). Para grabar ceremonias, caminos, montañas e iglesias deben contar con la autorización de las autoridades de la comunidad.

El documentalista indígena colabora con su comunidad en la construcción de la memoria colectiva, que se refleja con el diálogo que establece con los habitantes y con los protagonistas, la voluntad de escuchar las propuestas de ancianos, autoridades y habitantes. Esta colaboración realizadorcomunidad es posible por dos circunstancias: por un lado, las comunidades rechazan ser grabadas sin su consentimiento, y por el otro, se ha desarrollado entre los documentalistas una conciencia de trabajo colectivo con los miembros de su comunidad. Juan López Intzín, Xuno, quien se ha dedicado a documentar las tradiciones de Xojlej, dice que a él se le permite videograbar porque, aparte de que es originario de esa comunidad, colabora con los habitantes. Lleva, por ejemplo, cohetes o incienso en las celebraciones. Al concluir el documental, regresa a la comunidad, lo exhibe en la casa de la cultura, escucha propuestas, y cuando lo ha terminado completamente, entrega una copia a cada personaje involucrado: "solo así me siento con la libertad de mostrarlo a los demás; antes no lo puedo hacer, esa es mi ética personal y profesional" (comunicación personal, 23 de marzo de 2018). En ese camino de colaboración y reciprocidad, el documentalista se transforma. Xuno dice que ahora comprende más el pensamiento en la sociedad tzeltal, y en especial el ch'ulel, el alma o la conciencia de los tzotziles y tzeltales.

Para Martiniano Hernández, las personas de las comunidades son "resistentes al material realizado por gente de fuera"; porque sienten que no están representadas y porque "no devuelven nada a los pueblos originarios" y "en muchas ocasiones desvirtúan la realidad" (comunicación personal, 8 de febrero de 2017). Para él, un realizador que pertenece a la comunidad goza de dos ventajas: por un lado, conoce la cosmovisión del pueblo y diversas temáticas de interés, y por el otro, se involucra en la gestión de las necesidades de los habitantes.

Las velas, el posh, los cohetes y el incienso abren las puertas de los documentalistas en las comunidades indígenas, también cierta gratificación para los actores principales, una práctica impuesta por realizadores mestizos (López Intzín, 23 de marzo de 2018). En Don de Ser, un documental financiado por Ambulante con 20 mil pesos, al actor principal se le pagó mil pesos por su participación, y al alférez, 500. Los protagonistas cobran cuando el realizador no pertenece a la comunidad porque invierten tiempo y el material, argumentan, podría ser comercializado. Esto, asegura Samuel Ávila Ledezma (comunicación personal, 15 de noviembre de 2017), no sucede en las comunidades zoques. Si el documentalista es de la comunidad, contribuye, pero con apoyos, generalmente en especie, para los rituales y fiestas, algo común en las celebraciones indígenas en Chiapas, en donde todos aportan lo que pueden: maíz, cacao, posh, incienso o cohetes.

Hay pocas variantes entre realizadores tzotziles, tzeltales, tojolabales y zoques, en cuanto al proceso de elaboración de documentales. Samuel Ávila Ledezma, de habla zoque, cuando tiene un proyecto, se reúne con miembros de la comunidad, les plantea el tema, para saber si están de acuerdo, y no es raro que modifique la propuesta, para que "sean ellos quienes digan qué se debe grabar o qué desechar" (comunicación personal, 15 de noviembre de 2017).

Debido a que otros documentalistas se habían acercado a las comunidades zoques, pero después de grabarlas no habían regresado, Samuel Ávila enfrentó la desconfianza de los pobladores, no obstante que es hablante de esa lengua. Sin embargo, después de ofrecer un nuevo trato, basado en la reciprocidad y en la colaboración, ha podido realizar documentales, los cuales una vez enriquecidos por la comunidad, entrega una copia a los actores principales.

Elena Gómez Pérez trabaja con los tojolabales, que es a la par que los zoques, los que poseen menos registros videográficos. Al establecer un tema, lo primero que hace es hablar con las autoridades del lugar, para explicarles el propósito de la grabación y solicitarles permiso. En algunas ocasiones sus propuestas han sido rechazadas, pero cuando son aceptadas, inician las tareas de grabación, 
de diálogo con los involucrados y, finalmente, de edición, que para ella resulta la más extenuante, porque debe conservar la voz de la comunidad, sus preocupaciones, intereses y deseos de posicionar un tema determinado.

\subsection{PERSONAJES Y ESCALETAS}

Después de que el documentalista obtiene permiso de la comunidad y recursos para la realización del trabajo, procede a la localización de los protagonistas, quienes son fundamentales porque enlazan, exponen ideas y detonan la historia. Para lograrlo, busca a personas que conozcan un tema, y que puedan transmitir vivencias, testimonios y sentimientos; sino son capaces de comunicar emociones, ocupan un plano secundario lo que obliga a utilizar otros recursos narrativos. Debido a que el protagonista constituye el punto nodal del discurso, el documentalista dedica tiempo a encontrar a los personajes adecuados. A veces el camino es corto porque de antemano ha pensado en algún familiar, amigo o conocido. Con esos personajes, que son el alma de la historia, viaja, dialoga, negocia, escucha propuestas y les solicita determinadas acciones. Sin embargo, hay documentales sin personajes principales, en donde las emociones pueden desprenderse de la voz en off o de imágenes de objetos y ambientes, como casas, paisajes, dibujos, mapas, calles, música, ruidos, silencios 0 audios de archivo.

Los documentalistas investigados siguen estrategias similares de preproducción, producción y postproducción. Rosa Amelia Hernández Gómez, quien ha explorado los cortometrajes de ficción, escribe un guion técnico de movimientos de cámara, que por supuesto registra modificaciones; traza un storyboard, efectúa posteriormente la grabación y concluye con el montaje y la edición. Juan López Intzín, Xuno, traza una escaleta sobre la tradición que desea registrar, sujeta a modificaciones, según sugerencias de la comunidad:

En un ritual, la gente actúa naturalmente y luego sigues secuencias; por ejemplo, hacer una escaleta de una fiesta, sí se puede. El primer día voy a registrar al músico; claro, para eso debí haber seguido un ritual o una fiesta o por lo menos haber hecho 2 o 3 entrevistas, para saber cuál es el proceso de la fiesta y con base en eso hago una pequeña planeación: el músico sale a las 5 de la mañana, entonces yo debo llegar con él a las 4:30 de la mañana y si quiero filmar cómo se coloca su vestimenta, entonces llego más temprano (López Intzín, comunicación personal, 8 de noviembre de 2017).

Xuno prioriza la imagen y procura captar con nitidez el audio y el ambiente. Es un proceso laborioso que no siempre arroja resultados satisfactorios, debido a ruidos indeseables. Graba suficiente material, para descartar el inservible. Maricela Sánchez sigue, en sus producciones, lo aprendido en Ambulante: primero, delimita el tema, posteriormente escribe un guion y un storyboard, continúa con el rodaje y concluye con el montaje y la edición. En la posproducción, aparte de los trabajos de edición de video y de audio, que son fundamentales, traduce los diálogos y los subtitula en castellano y/o en inglés. El director y el editor seleccionan los encuadres, la música, los diálogos, las imágenes y los audios que marquen el ritmo adecuado y otorguen coherencia para que el espectador comprenda el mensaje. "Lo más complicado es la edición, todo tiene su complejidad; cumplo, por supuesto, con las etapas de preproducción, producción y postproducción, pero la edición es bastante compleja" (Martiniano Hernández, comunicación personal, 11 de febrero de 2018).

\subsection{MEDIADOR ARTíSTICO}

El documentalista indígena busca crear espacios de experiencias compartidas. Escucha, por eso, las críticas y comentarios que se emiten en las primeras exhibiciones dentro de la comunidad. Piensa en la colaboración como el elemento que engloba ese flujo de conocimientos cuyos trozos se reúnen para ser compartidos. Su propósito es que los documentales alienten y propicien la convivencia, fomenten las tradiciones, revaloren la memoria y promuevan el diálogo intercultural. También que sanen heridas, que defiendan derechos, que se respete al anciano como símbolo de sabiduría, y que se otorguen mayores espacios de participación a las mujeres. El orgullo de pertenencia a las comunidades no lo crean solo los documentales, pero sin duda contribuyen a fortalecerla. Surgen deseos de reivindicación de lo propio, de los tejidos, de la lengua, de la medicina tradicional, y del tiempo pausado de estos pueblos, rara vez tomados en cuenta por los medios comerciales.

No obstante que se escuchan observaciones, sugerencias y críticas de los protagonistas y de las autoridades locales, la última palabra la 
tiene el documentalista. Él es quien debe tomar la decisión final, pero haber dialogado con los involucrados, le permite contar con un marco más amplio para priorizar las necesidades y la voz de la comunidad. No se asumen resoluciones colectivas en el guion ni en el discurso narrativo, porque el documentalista entiende que sería un trabajo tardado y, posiblemente, sin conclusión. No pierde las esperanzas de lograrlo, pero por el momento nadie ha conseguido un producto colectivo total.

En el proceso de convertirse en documentalista, se registra una toma de conciencia de sus raíces. El realizador entiende que pertenece a una comunidad, a la que a veces había negado. Estrecha sus vínculos, valora los trajes tradicionales, comienza a hablar de nueva cuenta la lengua -que había relegado-, y participa en reuniones ejidales, romerías y fiestas ceremoniales. Es un retorno a los orígenes que desea contagiar a sus compañeros, y a los jóvenes, que emigrados o no, se apartan de la música y la danza tradicionales, para marchar al mundo del consumo comercial globalizado.

El trabajar como documentalista lo empuja a preguntarse quién es, cuáles son sus orígenes, a qué cartografía social pertenece y qué debe privilegiar en sus proyectos. Los 7 realizadores aquí estudiados posicionan su pertenencia étnica y el derecho a habitar dos mundos: el mestizo y el indígena. El documental se convierte en un camino hacia la identificación, la búsqueda de una identidad propia, siempre móvil, y la reconstrucción de una memoria colectiva colaborativa.

Como documentalista, se convierte en un mediador artístico que busca la transformación y el desarrollo cultural de su comunidad a través del reconocimiento de su propio legado, de la defensa de causas comunes y de la construcción de memorias colectivas. Con esto pretende también empoderar a sus comunidades en un proceso que "promueve y favorece que los individuos, grupos y comunidades conquisten más poder para lograr un mayor dominio de sus vidas, así como construir un entorno que permita una mayor calidad de vida y de bienestar" (Moreno, 2016, p. 68). Un riesgo del documentalista indígena es la pretensión de querer hablar por la comunidad, que no es más que "paternalismo estético y político” (Colombres, 1985, p. 27). El documentalista es un mediador entre la comunidad, en donde elaboró el documental, y las comunidades del exterior que verán su producto audiovisual, en donde posiblemente se abra el diálogo intercultural. Es una especie de cooperante cultural en el entorno de su comunidad, y esa es una de sus preocupaciones, porque se propone alertar, concientizar, revalorar las tradiciones que considera necesarias y combatir aquellas que no dignifican a las personas, como la inequidad de género. Hay temas todavía vedados, como la homosexualidad.

Al constituirse en un producto intercultural, de ida y vuelta de la palabra y de las imágenes, posibilita el surgimiento de propuestas personales, de creaciones artísticas, dentro de esta particular "cuasi-industria creativa" (Mejía, 2017). Por supuesto, que se puede argumentar que la misma capacitación de indígenas en el manejo de técnicas audiovisuales es una imposición colonialista, pero sería peor que no se tuviera la posibilidad de armar narrativas propias. El documentalista indígena se muestra satisfecho con sus logros artísticos, pero sabe que la realización es un arte comunitario porque involucra "a la comunidad en el proceso de creación” (Moreno, 2016, p. 43), y que puede impulsar el renacimiento, aprecio y valoración de su cultura. Este arte comunitario conlleva al "desarrollo cultural comunitario", en el sentido de "community cultural development" de Nardone (en Moreno, 2016, p. 42), es decir, al "desarrollo comunitario basado en el arte (art based community development), que sería concebido como "el trabajo de artistas, organizadores y otros miembros de la comunidad que colaboran para expresar identidad, preocupación y aspiraciones a través de las artes y medios comunicacionales" (Golbard, en Moreno, 2016, p. 43). Esto se palpa con el surgimiento de nuevos documentalistas, generalmente jóvenes, que se suman a esta actividad, y que conciencian los deseos de realización personal y colectiva.

\subsection{COLABORACIÓN ENTRE ACADÉMICOS, CINEASTAS Y DOCUMENTALISTAS}

En la producción de documentales indígenas, se puede observar la cooperación existente entre organizaciones y cineastas con experiencias que deciden trabajar con personas interesadas en registrar los acontecimientos de una comunidad. Ojo de Agua, una organización oaxaqueña, dirigida por el cineasta Guillermo Monteforte, ha impartido talleres de capacitación en comunidades adherentes 
zapatistas de Chiapas. La Organización de Médicos Indígenas del Estado de Chiapas, a través de su departamento de comunicación, que coordina el antropólogo visual, de origen tzotzil, Pedro Agripino Icó Bautista, fomenta la realización de documentales sobre práctica de parteras y conocimientos de medicina herbolaria de comunidades indígenas. La Escuela de Cine Video Mundos Inéditos, A. C., creado por el videoasta tzotzil Pedro Daniel López López, desde 2010 organiza con el Centro de Capacitación Cinematográfica de la Ciudad de México, talleres de iniciación sobre el documental con jóvenes indígenas. Ambulante Más Allá ha formado siete generaciones de documentalistas indígenas, entre los que se cuentan Juan Antonio Méndez, Amelia Hernández, Bernardino López, Cristina Vázquez, Maricela Culej, Ambrosiana Pablo y Néstor Jiménez. Ambulante, aparte de capacitar a documentalistas, ofrece foros de exhibición en México y en el extranjero, para exponer las mejores producciones indígenas. El Taller Cuéntamelo Filmando, que se enfoca a temas educativos, ambientales y culturales, apoya en la capacitación; el Campamento Audiovisual Itinerante de la Asociación Calenda Audiovisual, con sede en Oaxaca, fomenta el desarrollo de habilidades artísticas entre niños y jóvenes sobre cine comunitario; la Escuela de Cine Documental de San Cristóbal de Las Casas capacita en cine etnográfico a egresados de licenciaturas, y el Centro de Capacitación Cinematográfica Con Patas trabaja con indígenas de Chiapas y de Oaxaca. Participan también Mundos Inéditos, Promedios de Comunicación Comunitaria, CIESAS, UNICH y Cesmeca de la UNICACH.

El otro nivel de colaboración, sin lo cual difícilmente se producirían los documentales, es el financiero. Hay organizaciones regionales, nacionales e internacionales que apoyan la elaboración de documentales con cantidades que van de los 20 a los 50 mil pesos (1000 a 2500 dólares). Estos montos, desde luego, no posibilitan que los documentalistas se dediquen de tiempo completo a la creación audiovisual. Deben trabajar para dependencias gubernamentales, como Celali, o instituciones educativas, para obtener ingresos regulares. La mayoría elabora sus documentales en el tiempo libre. Las principales instituciones que apoyan con financiamiento a los cineastas son el Consejo Nacional para la Cultura y las Artes, la Comisión Nacional para el Desarrollo de los Pueblos Indígenas, Ambulante Más allá,
Fundación Rockefeller, W. K. Kellog y Comunidad del País vasco.

\subsection{EXHIBICIÓN EN LAS COMUNIDADES}

El documentalista indígena mantiene lazos con su comunidad, que contempla la exhibición. Como parte de sus obligaciones, que asume de forma individual, está presentar los audiovisuales en casas del pueblo, canchas, ferias, casas particulares o casas de cultura. Para él no solo significa mantener la puerta abierta, en caso de planear un nuevo documental, sino contribuir al autoconocimiento de la comunidad, al registro de la música, de las danzas, de la voz de las mujeres y de los ancianos, en fin, de la memoria colectiva.

En las comunidades presenta un trabajo prácticamente sin ediciones en donde lo que más importa es mostrar lo grabado: rostros, casas, perros, cerros, pasos, ejecutantes, la colectividad toda. Hay integrantes de la comunidad que reclaman su participación en el video, porque, rara vez tienen la oportunidad de verse representados. El cineasta cubano Julio García Espinosa (2010) ha llamado a este tipo de realización, "el cine imperfecto", porque interesa menos la estética que la oportunidad de otorgar voz e imagen a los habitantes, tradicionalmente marginados. "El carnaval de Tenejapa, por ejemplo, tuvo una duración de 20 horas, pero para exhibirlo en circuitos de cine debió reducirse a una hora. Para sentir que son parte del documental, aunque no aparezcan las personas, los habitantes de la comunidad desean que queden registradas sus casas o sus cosas" (Samuel Ávila, comunicación personal, 11 de noviembre de 2017). La exhibición sin cortes tarda entre 10 y 20 horas, porque se trata de escuchar las voces de los participantes y de las autoridades, quienes sugieren cambios o nuevos relatos. Los documentales adquieren en los pueblos un alto valor comunicativo porque abordan temas que interesan a los habitantes y porque están narrados en sus propias lenguas.

Estos videos tienen más demanda en las comunidades en donde se realizó el documental. Ahí están unos receptores activos que cuestionan, que lamentan, que critican, pero que también reconocen los aciertos logrados por el documentalista. Ahí se proyecta una y otra vez el documental, y se considera un honor aparecer y verse en las ceremonias, los rezos y las tradiciones. 
El documentalista, aparte de mantener un diálogo con la comunidad (reuniones para definir temas, grabar y recoger opiniones sobre el material), colabora con organizaciones y realizadores extranjeros, en especial, con colombianos por su producción videográfica con enfoque pedagógico; con argentinos, al participar regularmente en la Muestra Latinoamericana de Cine Indígena y Comunitario Arandu; con chilenos, de la etnia mapuche y su cine militante, así como con bolivianos, brasileños, peruanos y guatemaltecos. El Festival de Cine y Video Indígena de Morelia, que se organiza desde 2005, es un foro importante de exhibición, colaboración y discusión de documentalistas, así como el Festival Geografías Suaves/Cine Video Sociedad, el encuentro Contra el Silencio Todas las Voces y el Festival Internacional de Cine y Video Indígena, organizado por la Coordinadora Latinoamericana de Cine y Comunicación de Pueblos Indígenas. Algunos documentalistas han participado en el Festival de Cine y Video Indígena del National Museum of the American Indian en Estados Unidos, el Imagine Native Festival, el Festival Internacional de Cine de Amiens en Francia, el Festival de Cine Latino de Toulouse, el Audiovisual Universo de los Pueblos Indígenas Showcase en España, el Festival Internacional de Cine y Video Indígena del Smithsonian Museum en Nueva York, el Native Film de Southern en California y el Indian Center de Nuevo México.

Saúl Kak ha exhibido en los festivales Visions Du Réel en Suiza, Cinema Vérité en Irán, Watch Docs en Polonia, Slamdance, Ann Arbor Film Festival y Wexner Art Center en Estados Unidos. Elena Gómez Pérez, quien muestra sus videos en las ferias y casas de la cultura de los municipios de Las Margaritas, de La Trinitaria y de Comitán, participa en festivales de cine nacionales, así como los demás documentalistas indígenas. Hacen falta, por supuesto circuitos de exhibición, sobre todo en el interior del estado, porque aun cuando se emplee YouTube, el internet en Chiapas abarca el 30 por ciento de la población y está concentrado en zonas urbanas.

Los foros, tanto nacionales como internacionales, son numerosos, y se requieren apoyos de organizaciones para asistir a los diferentes festivales y encuentros de creadores de documentales, lo cual no es fácil de conseguir. No obstante, estos lugares de exhibición, una de las dificultades, quizá la mayor, es que los documentales aparezcan en circuitos en donde generen recursos económicos para los directores. Muchos documentales quedan resguardados por años en las oficinas de las instituciones que financian la realización, sin que sean exhibidos más allá de las comunidades.

\section{CONCLUSIONES}

El documentalismo en Chiapas ha atravesado por tres etapas importantes. En la primera, el documentalista registraba a los indígenas como "el otro", lo exótico, lo diferente, parte de un museo de piezas inamovibles y anecdóticas, que contribuían a la conformación folclórica del país y la heterogeneidad de un México de unidad nacional, renovado e incluyente. En la segunda etapa, el documentalista tuvo un mayor acercamiento a las comunidades, a sus sentires, necesidades y aspiraciones, pero seguía siendo el de "fuera" quien captaba con ánimo objetivo, ese mundo propicio para la antropología. En ese vuelco a la historia que ha sido la perspectiva poscolonial, los intercambios globales y el neozapatismo, permitieron el desplazamiento de artistas, cineastas y productores que incidieron en la formación en cinematografía de jóvenes indígenas letrados, quienes han comenzado a construir narrativas visuales sobre sus comunidades y sobre ellos mismos, en una actitud de mayor respeto a los valores comunales.

Ahora, el documentalista indígena (ver Anexo) es egresado de universidad, y ha cursado diplomados y talleres sobre cine en diferentes instituciones. Se mueve, en ese sentido, en el mundo mestizo académico, de la cuasi-industria del cine independiente, y en el mundo comunitario de su etnia. Es consciente de que contribuye a la construcción de una memoria colectiva, y subalterna, en comunidades tradicionalmente invisibilizadas, no obstante que Chiapas es el segundo estado en México con mayor población indígena (1 millón 286 mil indígenas de un total de 5 millones 217 mil habitantes, según Encuesta Intercensal: Chiapas, 2015). Al final, y es el propósito del documentalista, busca accionar la conciencia, reflexionar y posicionar temas en la agenda de discusión de la comunidad.

En el ejercicio del documentalismo existe un proyecto decolonizador para dar voz y empoderar a las comunidades indígenas. Ese ejercicio sería imposible sin la colaboración que establecen los documentalistas con los protagonistas y las autoridades locales. En el 
empleo de cámaras se observa un ánimo de reivindicación, de construcción de la memoria colectiva, de apropiación de técnicas audiovisuales para presentar la voz y la imagen de las comunidades, y verse, no a través del espejo del extraño, sino del espejo propio. La representación de la comunidad no es, por supuesto, uniforme. Hay diferentes percepciones: negativas, positivas, idealistas, pero la colaboración con las personas permite que las imágenes se acerquen más a la realidad.

Hay una empatía del documentalista con la comunidad con la que trabaja, quien no siempre está de acuerdo con lo expresado por los protagonistas. Aun así, recoge y expone voces variadas, y si es necesario, las contrapuntea con otros pareceres. Se niega a instruir a los personajes sobre lo que deben decir; por el contrario, busca reflejar el sentir profundo de los rezadores, mayordomos, ancianos y mujeres. No graba sin la autorización de los protagonistas o de las comunidades. La aprobación de los participantes es fundamental, porque considera que sus producciones son colectivas, y aunque intenta imprimir un estilo personal, la contribución mayor, y así lo expresan, es de la comunidad.

No se debe caer en la idea de que el documentalista indígena es el único portador de la verdad sobre los acontecimientos de su comunidad. Hay que verlo como un mediador artístico, quien, por pertenecer a un grupo étnico, puede palpar necesidades y tener acceso más fácil a los protagonistas. El empleo de una lengua común y de relaciones familiares y sociales le permiten acercarse a las personas y temáticas de interés.

Alejadas del control de los medios de difusión masiva, la única oportunidad que tienen las comunidades es construir su imagen, su voz, su mensaje, con mediadores propios. Es a través de ellos que difunden los problemas que enfrentan y la necesidad de darles respuesta.

El ritmo que marca el documentalista es la lentitud para evocar la convivencia sin prisas del mundo indígena, con planos sostenidos en varios segundos, en una narración pausada, apacible, sin cortes vertiginosos propios de las películas comerciales. La música que acompaña a las realizaciones son las que se interpretan en las propias comunidades, desde la tradicional hasta el rock y el ská, cantadas en lenguas indígenas. Los ruidos que aparecen son los que envuelven a los pueblos: la lluvia constante, las tormentas del verano, los cantos de aves, el sonido del viento que agita las hojas, los largos silencios que invitan a la quietud, la soledad, la búsqueda del alma y la ausencia del mundo. El documental es un producto híbrido: instrumento para la obtención de datos y artefacto cultural.

El denominador común de estas
producciones y la intención de los documentalistas estudiados es colaborar y cooperar con sus comunidades para lograr un sentido de pertenencia y de valoración de tradiciones, cultura y sentimientos de solidaridad. Los temas tienen que ver con la defensa del territorio comunal, el cuidado de la naturaleza, el rescate de conocimientos tradicionales, las prácticas médicas y sociales significativas, y los movimientos y organizaciones comunitarias. Hay proyectos de reciprocidad, de colaboración, de realización y exhibición de los documentales en las diversas comunidades de México, pero han sido difíciles de concretar por los desafíos económicos y lingüísticos. No hay, por supuesto, comunidades estáticas, y eso lo sabe el documentalista, que está consciente de que sus registros pueden convertirse en la última oportunidad de observación de una festividad.

Los documentales tienen un rasgo de cortesía, de "humanismo", que buscan comprender a la comunidad, exaltar sus valores, aunque en ocasiones, abordan temas que consideran injusto que se sigan alimentando, como el machismo, la desigualdad de género, el alcoholismo y la violencia. Visto así, el documental indígena no es un registro folclórico de las comunidades, sino un proyecto político con pretensiones de contar, pero también de provocar algo: reflexión, protesta, solidaridad, hermandad, reconocimientos y diálogos interculturales. No es un producto neutro. El hecho de grabarse en una lengua indígena es en sí mismo un acto político de toma de conciencia y de rebeldía. Los realizadores hacen propio un instrumento que antes no estaba a su alcance; retoman aspectos técnicos de fuera y aspectos culturales del interior de la localidad para fusionar estos dos mundos, con el propósito de reivindicar la adscripción cultural de la que forman parte.

Los primeros documentalistas indígenas aprendieron que era necesario establecer un diálogo permanente con los involucrados en las producciones; que no era un producto personal, sino colectivo. Sobre la marcha se dieron cuenta que, aunque tuvieran un proyecto, este debía ser negociado con la comunidad, y que cabía la posibilidad de que no fuera aceptado. No se podía llegar con la cámara al hombro y grabar lo 
que marcara el guion; que era imprescindible hablar con las autoridades locales, explicar los propósitos y detallar los aspectos de la grabación

Ahora, el documentalista indígena sigue una ruta colaborativa, que aun cuando no se enseñe en los cursos de cine, resulta vital en el proceso de realización y de exhibición, porque más allá de la pretensión de imprimir un sello artístico personal al documental, debe contribuir a empoderar a sus comunidades a través de la palabra y de las imágenes.

\section{NOTAS}

1 Martiniano Hernández Gómez, originario de San Juan Chamula, estudió economía en la Universidad Autónoma de Chiapas (Unach) y la maestría en Desarrollo Rural en la Universidad Austral de Chile. Es profesor de la Universidad Intercultural de Chiapas (Unich). Su primer documental, Y me vine a San Cristóbal, en donde narra la emigración de chamulas hacia la periferia de San Cristóbal de Las Casas, fue bien aceptado en los circuitos de exhibición urbanos, pero en su comunidad no causó mayor asombro "al ser visto como un acontecimiento normal entre los habitantes" (Hernández Gómez, comunicación personal, 20 de febrero de 2018). Su segundo video, X-Juliaon (Soy Julia), debido a la temática sobre homosexualidad, rara vez abordada en su pueblo, prefirió no mostrarla en la comunidad, pero sí en festivales de cine y espacios universitarios. Martiniano Hernández explora temas poco convencionales entre los documentalistas, con una intención clara de no registrar solo usos, costumbres y ceremonias. Actualmente dirige un proyecto sobre el posh en Huixtán (una bebida alcohólica típica entre los tzotziles) y en un viaje que realizó a Perú, Bolivia, Ecuador, Colombia y Argentina.

2 Aunque Rosa Amelia (Zinacantán, 1986) también se apellida Hernández Gómez, no es pariente de Martiniano. Los apellidos en esta etnia a menudo se repiten. Ella estudió la Licenciatura en Comunicación Intercultural en la Unich. Ha cursado talleres sobre realización de documentales en el Centro de Capacitación Cinematográfica (CCC) y de Ambulante Más Allá. Ha dirigido Niños de la calle, Aguas sucias y Zinacantán, y ha participado en diversas creaciones colectivas. Actualmente realiza el documental Noosfera, que trata sobre la interpretación de los sueños entre los tzotziles.

3 Juan López Intzín, Xuno, (Tenejapa, 1974) se interesó por la fotografía desde sus años como estudiante de Sociología en la Universidad Autónoma de Chiapas. Con una cámara prestada fotografió a su abuelo y las tradiciones de Xoxlej, su comunidad. En el 2001, al ingresar al Centro Estatal de Lenguas, Artes y Literatura Indígenas (Celali), comenzó a videograbar actividades de la institución; después, al asumir la dirección del departamento de producción audiovisual, documentó rituales y tradiciones de diversos pueblos, al tiempo que acreditó un curso de antropología visual organizado por el Centro de Investigaciones y Estudios Superiores en Antropología Social (CIESAS) y por el Centro de Estudios Superiores de México y Centroamérica (Cesmeca) de la Universidad de Ciencias y Artes de Chiapas (Unicach). Actualmente, documenta el mundo de los espíritus, de los cerros, las cuevas y la tierra de Tenejapa.
4 Maricela Sánchez Gómez (Tenejapa, 1994) realizó su primer corto documental de 40 segundos cuando estudiaba el bachillerato en San Cristóbal de Las Casas. Con ese trabajo, que abordó el problema de la contaminación, ganó en 2008 el primer lugar estatal de realizaciones breves en Chiapas. En 2009, con un documental sobre maternidad temprana, obtuvo el segundo lugar estatal. Estos logros fueron alicientes para profundizar en el periodismo audiovisual y cursar talleres con Ambulante Más Allá. En esos cursos, aprendió manejar la cámara y a emplear recursos de narrativa audiovisual. Participó en el documental El Naíl, realizado en Ambulante: "Ahora siento que el documental es una manera para desenvolverme como mujer y poder transmitir sentimientos, rostros, encuentros, momentos y tiempos con la cámara" (comunicación personal, 5 de febrero de 2018). Dedicarse a la realización de videos, le ha posibilitado romper con el encorsetamiento machista en su comunidad, pero también a revalorar los lazos de solidaridad. Al involucrarse como documentalista decidió usar enaguas, algo en que su padre no estaba de acuerdo, porque lo considera un signo de control: "Cuando era niña, mi papá no me dejó ponerme enagua; siempre me vistió como mestiza, me cortaba el cabello; mi mamá quiso que usara enagua, faja y el rebozo de lana, pero mi papá siempre me decía que con pantalón mi vida iba a ser mejor, entonces opté por los pantalones y los vestidos; crecí así" (Sánchez, comunicación personal, 10 de agosto de 2017). Su despertar por la conciencia de género, la involucró con organizaciones que fomentan estos derechos $y$, al convertirse en madre a los 16 años, aparte de que la colocó en perspectiva abordar el tema de los embarazos tempranos entre indígenas, la llevó a formar parte del Comité Promotor para una Maternidad Segura y Voluntaria en Chiapas. Aunque el número de documentalistas mujeres indígenas es menor que de los hombres, se observa cada vez más participación de ellas en esta actividad (12 de 37), si se compara, con el año 2000 , en que no figuraba ninguna en la lista.

5 Cuando estudiaba la Licenciatura en Economía en la Unach, Samuel Ávila Ledezma (Chapultenango, 1975) descubrió que le apasionaba la realización de documentales. Como otros jóvenes cursó un diplomado en antropología visual impartido por CIESAS y Cesmeca; posteriormente, empezó a registrar rituales y festividades en diferentes comunidades indígenas. Aunque es de origen zoque, sus primeros documentales los desarrolló en Tenejapa, un pueblo de habla tzeltal. Su trabajo audiovisual le permitió ingresar en Celali, la institución gubernamental creada para registrar prácticas culturales indígenas en Chiapas. Su documental El padre del pueblo enfatiza en la importancia, cada vez más erosionada de los ancianos como memorias vivas y guías espirituales. $\mathrm{Ha}$ colaborado en los documentales Ya no estoy para esos trotes, Alfareras de Zinacantán, Alfareras de Tapalapa, Alfareras de Amatenango del Valle, El volcán y su dueña, Mundos zoques, El balché la bebida ritual de los lacandones y 30 años de la erupción del volcán Chichonal, así como diversas realizaciones sobre festivales zoques, tzeltales y tzotziles. Samuel Ávila se desempeña también como fotógrafo y locutor de radio.

6 Saúl Méndez Díaz, Saúl Kak, (Rayón, 1985), egresado de la Licenciatura en Artes Visuales de la Universidad de Ciencias y Artes de Chiapas, se interesó desde niño por el documental. Piowachuwe, de Juan Francisco Urrusti, le dejó profundas huellas: "Me llamó la atención la imagen, la historia y la identificación que había de las personas con la imagen; empezaban a recordar a las personas, a sus familiares, había momentos de diversión, eso me quedó en el corazón y en la mente" (comunicación personal, 15 de enero de 2018). Kak trabaja en comunidades zoques, las menos documentadas en Chiapas, con registros de todo tipo: 
problemas medioambientales, tradiciones, cápsulas de orientación y entrevistas, los cuales distribuye en su canal de Youtube (https://www.youtube.com/user/saulkak). Actualmente realiza un documental sobre migrantes zoques. Desea incursionar en la ficción, pero se lo impiden las dificultades económicas.

7 Elena Gómez Pérez (Las Margaritas, 1984) es de las pocas mujeres documentalistas, y la única entre los tojolabales. Se ha dedicado a registrar romerías. Estudió la Licenciatura en Ciencias de la Comunicación en la Unach. En 2009, cuando fue prestadora de servicio social en Celali, elaboró un video con el propósito de crear conciencia sobre el valor de las tradiciones. A partir de entonces, inició su labor creativa como documentalista, la cual desarrolla en sus tiempos libres que le permite su trabajo como profesora en la Escuela Preparatoria Lázaro Cárdenas, en Las Margaritas. Los financiamientos los ha obtenido de la Comisión Nacional para el Desarrollo de los Pueblos Indígenas. En su discurso audiovisual cobra importancia las tradiciones, visualizada en los ancianos, y la crítica de la preponderancia masculina en esas tradiciones y la marginalidad de las mujeres.

\section{REFERENCIAS BIBLIOGRÁFICAS}

- Ardévol, E. y Muntañola, N. (2001). Representación y cultura audiovisual en la sociedad contemporánea. Barcelona: UOC.

- Carrera, P. y Talens, J. (2018). El relato documental. Efectos de sentido y modos de recepción. Madrid: Cátedra.

- Colombres, A. (1985). Cine, antropología y colonialismo. Buenos Aires: Ediciones del Sol.

- Cusi, E. (2005). Más allá de la hibridad: los medios televisivos y la producción de identidades indígenas en Oaxaca, México. Liminar Estudios Sociales y Humanísticos. 3 (2), 34-47. DOI: https://doi.org/10.29043/liminar.v3i2.181.

- Darling, J. (2008). Latin America, Media, and Revolution: Communication in Modern Mesoamerica. N.Y.: Palgrave Macmillan US. DOI: https://doi.org/10.1057/9780230612006.

- Diccionario de la Lengua Española (2018). Real Academia Española. [Entrada: colaborar] Recuperado de: https://dle.rae.es/?id=9j7x3u4.

- Encuesta Intercensal (2015). Principales resultados de la Encuesta Intercensal 2015: Chiapas / Instituto Nacional de Estadística y Geografía. México: INEGI, (c2015) Recuperado de:

http://internet.contenidos.inegi.org.mx/contenidos/Pro ductos/prod_serv/contenidos/espanol/bvinegi/producto s/nueva_estruc/inter_censal/estados2015/7028250797 27.pdf.

- García Espinosa, J. (15 de septiembre de 2010). Por un cine imperfecto. RUA. Revista Universitária do Audiovisual. Universidade Federal de Sâo Carlos, Brasil. Recuperado de: http://www.rua.ufscar.br/?s=Garc\%C3\%ADa+Espinos a.
- Henley, P. (2009). The Adventure of the Real. Jean Rouch and the Craft of Ethnographic Cinema. Chicago: The University of Chicago Press. DOI: https://doi.org/10.7208/chicago/9780226327167.001.0 001 .

- Hicks, J. (2007). Dziga Vertov, Defining Documentary Film. N.Y.: I.B. Tauris \& Co Ltd. DOI: https://doi.org/10.5860/choice.45-3107.

- Leyva, X. y Köhler, A. (2008). La ética de trabajo en el Proyecto Videoastas Indígenas de la Frontera Sur. En Dalton, M. (Ed.) Encuentros de Cine y Video Etnográfico 2003-2005: Celebración, Fiestas, Trabajo y Tradiciones. [publicación en CD]. México: CIESAS.

- Mejía, A. C. (2017). Un pan y un café. En Gordillo, C S. y Mejía. A. C. (Eds), Miradas urgentes: sujetos, estéticas y memorias del documental latinoamericano contemporáneo (pp. 338-383). Ciudad de México, México: Editorial Foc.

- Mora, H. (2010). El método etnográfico: origen y fundamentos de una aproximación multitécnica. En FQS Forum: Qualitative Social Research sozialforschung, 11 (2). art.10.

- Moreno, A. (2016). La mediación artística. Arte para la transformación social y la inclusión social y el desarrollo comunitario. Barcelona: Octaedro Editorial.

- Nichols, B. (2016). Speaking Truths with Film: Evidence, Ethics, Politics in Documentary. Oakland, CA: University of California Press. DOI: https://doi.org/10.1525/9780520964587.

- Nichols, B. (1997). La representación de la realidad: cuestiones y conceptos sobre el documental. Barcelona: Paidós.

- Smith, L. T. (1999). Decolonizing Methodologies. Research and Indigenous Peoples. London: Zed Books Ltd. DOI: https://doi.org/10.1111/aeq.12032.

- Spivak, G. (2009). ¿Pueden hablar los subalternos? Barcelona: MACBA. DOI: http://dx.doi.org/10.18172/cif.1533.

- Zirión, A. (2015). Miradas cómplices: cine etnográfico, estrategias colaborativas y antropología visual aplicada. Iztapalapa. Revista de Ciencias Sociales y Humanidades, (78), 45-70. DOI: https://doi.org/10.28928/revistaiztapalapa/782015/atc2 /zirionpereza.

- Zunzunegui, S. y Zumalde, I. (2019). Ver para creer. Avatares de la verdad cinematográfica. Madrid: Cátedra. 